\title{
Börükçü’den Bir Grup Siyah Figürlü Lekythos
}

\author{
Dr. Halime Aslan \\ Selçuk Üniversitesi Bozkır Meslek Yüksekokulu \\ Mimari Restorasyon Bölümü \\ ahalime@selcuk.edu.tr
}

Öz

Bu çalışmada, Muğla İli, Yatağan İlçesi, Yeşilbağcılar Beldesinde, Aladağ'ın batısında yer alan, Antik Karya Bölgesi sınırları içinde kalan Börükçü kırsal alanında bulunan beş adet siyah figürlü leythos değerlendirilmiştir. Börükçü lekythoslarından dört tanesi mezar (no. 12, 4-5), bir tanesi sondaj (no.3) buluntusudur. Börükçü siyah figürlü lekythosların tümü de omuzlu lekythos (shoulder lekythos - standart type) grubundandır ve Richter - Milne "Tip II Shoulder set offfrom body"lekythos grubu içinde yer almaktadır. Börükçü lekythoslardan, no.1, 2 ve 3'ün gövde üzerinde yer alan bezeme ve forma göre "'Beldam Ressamı ve Atölyesi Grubu", no.4'ün "Beldam - Haimon grupları" ile ilişkili örneklerden oldukları tespit edilmiştir. Benzer ve yakın örneklere göre, Börükçü siyah figürlü lekythosların hepsi MÖ 5. yüzyılın ilk yarısına tarihlendirilmiştir.

Anahtar Kelimeler: Börükçü, lekythos, siyah figür tekniği, "Beldam Ressamı ve Atölyesi Grubu"'.

\section{A Group of Black Figured Lekythos from Börükçü}

\begin{abstract}
In this study, five black- figured lekythoi from Börükçü area which is located in the west of Aladağ mountain, within the boundaries of the ancient Caria region ( in modern Yatağan/Muğla) have been examined. Four of them are grave gifts (no. 1-2, 4-5), and one of them is the sounding excavation find (no.3). All of the Börükcü black-figure lekythoi are in the group of "standart shoulder lekythos" and are in the"type II - shoulder set off from body" in the typology of Richter and Milne (Richter-Milne 1973). According to the types and the decorations on the body, the samples 1, 2 and 3 are related to the "Beldam Painter and Workshop Group" and the sample 4 is related to the "Beldam-Haimon Workshop". All the black figure lekythoi of Börükçü are dated to the first half of the fifth century BC in the light of similar and close examples.
\end{abstract}

Keywords: Börükçü, lekyhos, black figüre technique, "Beldam Painter and Workshop Group". 


\section{GíRIŞ}

Börükçü, Muğla İli, Yatağan İlçesi, Yeşilbağcılar Beldesinde, Aladağ'ın batısında yer alan, Antik Karya Bölgesi sınırları içinde kalan kırsal bir yerleşim yeridir. Stratonikeia antik kenti ile Lagina Kutsal Alanı'nı birbirine bağlayan, konum olarak İdemir, Kabasakız ve Aldağ mevkilerinden geçen ve her iki tarafında antik mezarların yer aldığı kutsal yol üzerinde bulunmaktadır ${ }^{1}$ (Söğüt 2012: 555) (Res. 1).

Börükçü alanındaki çalışmalar, Türkiye Kömür İşletmeleri Kurumu Genel Müdürlüğü'ne bağll, Güney Ege Linyitleri İşletmesi Müdürlügünün Muğla ili, Yatağan ilçesi, Eskihisar Ocağında, 2002 yılında yapılan madencilik faaliyetleri sırasında antik döneme ilişkin arkeolojik buluntulara rastlanması ile başlamıştır².

$\mathrm{Bu}$ çalışmada, kurtarma kazıları sırasında Börükçü alanından çıkarılan, Klasik Dönem'e tarihlendirdiğimiz, beş adet siyah figürlü lekythos ele alınmıştır. Börükçü siyah figürlü lekythoslarından dört tanesi mezar (no.1, no.2, no.4 ve no.5), bir tanesi sondaj (no.3) buluntusudur. Çalışma içinde değerlendirilen Börükçü siyah figürlü lekythosların tümü de omuzlu lekythos (shoulder lekythos - standart type) grubundandır ve Richter - Milne "Tip II Shoulder set off from body"3 lekythos grubu içinde yer almaktadır.

Börükçü siyah figürlü lekythosları bezemesine göre, gövde üzerinde sarmaşık (no.1, no.2) ve palmet (no.3, no.4) bulunan bitkisel bezemeliler ve omuz üzerinde ışın demeti bulunan (no.5) gövdesi siyah firnisliler olmak üzere iki özellik göstermektedir.

\section{Bitkisel Bezemeli Lekythoslar}

\section{Sarmaşık Bezemeliler}

No. 1 (Res. 2, Fig. 1)

Müze Envanter No: 1818, Kazı Envanter No: 03BM12 - PT01

Yükseklik: $15.0 \mathrm{~cm}$, gövde çapı: $6.5 \mathrm{~cm}$, kaide çapı: $4.5 \mathrm{~cm}$, cidar: $0.3 \mathrm{~cm}$

Hamur: Munsell 5YR 8/1 -8/2 (white-pinkish white)

Astar/Firnis: astar, Munsell 10YR 8/1(white), parlak ince siyah firnis.

Kulp tamamen kırık ve eksiktir; boyunda yapıştırma, yüzeyde yer yer aşınmalar görülür. Dışa doğru hafif yuvarlatılmış huni (trompet) ağızlı, uzun -dar silindirik boyunlu, kaideye doğru daralan silindirik gövdeli, orta bölümde iç bükey profil gösteren yüksekçe disk kaideli, boyundan omuza bağlanan ince, dikey şerit kulpludur. Boyun başlangıç ve bitiş noktasında kavisli, omuzlar belirgindir. Gövde kaideye yaklaştığı noktalarda keskince daralmalar göstererek kısa bir kaide boynu oluşturur. Kulp boyundan çıkarken hafifçe yükseltilerek yuvarlatılır ve omuz bitimine dik biçimde yerleştirilir.

Ağız içerden ve dışardan huni formun bitimine kadar, kırmızımsı astar üzerine, inceltilmiş siyah firnislidir. Boyun ve omuzda ışın demeti yer alır. Boyun bitiminde yer alan ışın demeti daha kısa iken, omuz üzerinde yer alan ışın demeti omuzu tamamen kapatacak şekilde daha uzundur. Gövdenin yarısı yukardan itibaren aşağıya doğru krem astar üzerine, iki sıra yatay siyah bant, meander, tek sıra yatay bant, dört sıra halinde kafes motifi ve tek

\footnotetext{
1 Börükçü yerleşimi için bk. Söğüt 2012: 553-586; Tırpan - Büyüközer 2010: 227-240; Büyüközer 2012: 127-146; Büyüközer 2013: 37-48; Gider 2014: 499-516; Tırpan - Büyüközer vd. 2016: 499-516.

2 İlk müdahale 2002 yılında Muğla Müze Müdürlüğü tarafından, o bölgede arkeolojik kazı çalışması yapan Lagina kazı ekibinden de yardım istenerek yapılmışır. 2003 - 2009 yılları arasında ise buradaki Kurtarma kazıları, Kültür Varlıkları ve Müzeler Genel Müdürlügü ile Türkiye Kömür işletmeleri Genel Müdürlüğü arasında yapılan bir protokole istinaden, Selçuk Üniversitesi'nden, Prof. Dr. Ahmet A. Tırpan başkanlığında yürütülen Lagina Kazı Ekibi tarafından gerçekleştirilmiştir.

${ }^{3}$ Tiplemeler için bk. Richter - Milne 1973: res. 93-98.
} 
sıra yatay bant bezemelidir. Bu sıralama (meander hariç) gövdenin ortasında ana motif olarak verilen, dalları, yaprakları ve noktalar halinde meyvesiyle işlenen sarmaşık bezemesinden ${ }^{4}$ sonrada devam eder. Sarmaşık bezemenin meyvelerinde kahverengimsi kırmızımsı firnislidir. Gövdenin alt bölümü ise aralarında kahverengimsi-kırmızımsı astar kullanılan, kabı çepeçevre saracak şekilde, kalınlı-inceli yatay, siyah firnis bantlıdır. Kaide üzeri ve kaide yan çeper ortasında da siyah firnis görülür. Mevcut kulp parçasından ve boyun ile birleşme yerinden görüldüğü kadarı ile kulp yüzeyi de dikey, siyah firnis bantlıdır. Bezeme konturları yüzeysel kazıma olarak verilmiştir.

\section{No. 2 (Res. 3, Fig. 2)}

Müze Envanter No: 1819, Kazı Envanter No: 03BM12 - PT02

Yükseklik: $14.6 \mathrm{~cm}$, gövde çapı: $6.5 \mathrm{~cm}$, kaide çapı: $4.7 \mathrm{~cm}$, cidar: $0.3 \mathrm{~cm}$

Hamur: Munsell 5YR 8/1 -8/2 (white-pinkish white)

Astar/Firnis: astar, Munsell 10YR 8/1(white), ağız içi ve dışı 2.5YR 4/4 (reddsishbrown), boyun ve omuz 2.5 YR 5/4 ((reddsishbrown), parlak ince siyah firnis.

Boyunda yapıştırma ve yüzeyde aşınmalar görülür. Dışa doğru hafifçe yuvarlatılmış huni (trompet) ağızlı, uzun -dar silindirik boyunlu, kaideye doğru daralan silindirik gövdeli, orta bölümde iç bükey profil gösteren disk kaideli, boyundan omuza bağlanan ince, dikey şerit kulpludur. Boyun başlangıç ve bitiş noktasında kavisli, omuzlar belirgindir. Gövde kaideye yaklaştığı noktalarda daralarak kısa bir kaide boynu oluşturur. Kulp boyundan çıkarak omuz bitimine dik biçimde yerleştirilmiştir.

Ağız içerden ve dışardan huni formun bitimine kadar kırmızımsı - kahverengimsi firnislidir. Bezeme olarak, no.1 ile aynı biçimde boyun ve omuzda iki sıra ışın demeti, gövdede üstten itibaren sırayla, iki sıra ince yatay bant, meander, tek sıra yatay bant, kafes motifi, tek sıra yatay bant görülür. Ana motif olarak da dalları, yaprakları ve meyvesi ile sarmaşık bezemesi kullanılmıştır. Ancak no.2'den farklı olarak üstteki kafes motifi üç sıra halinde verilmiştir. Sarmaşık motifin dalları da, yanlara doğru daha yayvan ilerleyen no.1'e göre daha derli toplu ve daha düz uzanmaktadır. Sarmaşık bezemeli her iki örnekte de, dış konturlar yüzeysel biçimde kazıma olarak verilmiştir.

Sarmaşık bezemeli Börükçü lekythosların "Beldam Ressamı ve Atölye Grubu" ile bağlantılı örnekler arasında yer aldığı ve MÖ 5. yüzyılda sıklıkla kullanılan bir form oldukları anlaşılmaktadır. ${ }^{5}$ Batı Anadolu ve Akdeniz - Batı Kilikya bölgelerinden gelen Karaman (Doksanaltı 2011: 96, Fig.11-12.n), Silifke (Zoroğlu - 2009: 5-6, Lev. IV, no 1-8), Anamur (Yıldız 2013: Res.51-56, Res.60-62), ve Alanya müzelerinde (Yıldız 2013: Res.94-103) korunan lekythoslar, 'Börükçü lekythosları ile aynı grup içinde yer almaktadır. Benzer lekythoslardan özellikle Silifke Müzesi'nde korunan, MÖ 5. yüzyıla tarihli bir lekythos (Zoroğlu 2009: 5-6, Lev. IV, Fig. 4 (505)) form olarak no.1 ile çok yakın durmaktadır. Mainz Zentral Museum'dan MÖ 5. yüzyılın başlarına tarihli bir lekythosun (Büsing-Kolbe 1977: Lev.37, no 8) ise hem form olarak, hem de boyun- omuzdaki ş̧ın demeti, gövde üzerindeki sarmaşık bezemenin kapladığı alan, sarmaşık dallarının uzanma biçimi ve serbest çizgi

\footnotetext{
${ }^{4}$ Risser, "sarmaşık bezemesi" olarak tanımladığımız süslemeyi üzüm sarmaşığı ve arada yer alan meyveleri de üzüm salkımı olarak açıklar. bk. Risser 2003: 160

${ }^{5}$ Bu özellikleri taşıyan Beldam Atölye Grubu örnekleri için bk. Tuna-Nörling 1999: 10; Kurtz 1975: 84; Boardman 1996: 136; Haspels 1936: 170 - 111; Moignard 1989: 20, Lev.16, no 11-16; Büsing-Kolbe 1977: 77, Lev. 37, no 8; İşler 1973: 28, Lev.20, no 17-20; Giudice 1979: 29-30, Lev.45, no 1-2 (MÖ 475-450); Frere 1997: 39-40, Lev.22, no 6, 8-10 (MÖ 470-460); Knigge 1976: 37, Lev. 77; Geniere 1971: 9, Lev.11, Fig.12-15; Chease 1942: Lev. XXI, no 4; Bouzek 1990: 150, Lev.6, no 3; Alkaç 2006, 54-58, fig.4-5.
}

SEFAD, 2017 (38): 481-492 
hatları ile no.1 ile çok yakın benzerlik içindedir. Batı Kilikya Bölgesi'nden gelen ve Silifke Müzesi'nde korunan MÖ 5. yüzyıla tarihli başka bir lekythos (Zoroğlu 2009: 2, Lev. III, Fig.1. (1488)) ise gövde formu ve sarmaşık dallarının uzanma biçimi ile no.2' ye yakın durmaktadır. Bu yakın benzerlikler, Mainz Zentral Museum'da ve Silifke Müzesin'de korunan örnekler ile sarmaşık bezemeli (no1 - no2) Börükçü lekythosların aynı atölyelerde üretilmiş olma olasılıklarını düşündürtmektedir.

\section{Palmet Bezemeliler}

No. 3 (Res. 4, Fig. 3)

Müze Envanter No: 2060, Kazı Envanter No: 03BS09 - PT08

Yükseklik: $14.6 \mathrm{~cm}$, gövde çapı: $6.7 \mathrm{~cm}$, kaide çapı: $4.7 \mathrm{~cm}$, cidar: $0.4 \mathrm{~cm}$

Hamur: Munsell 5YR 8/1 -8/2 (white-pinkish white)

Astar/Firnis: astar gövde Munsell 2.5 YR 8/1 - 8/2 (white - pinkish white), kaide ve omuz 2.5 YR 5/6 (red), parlak ince siyah firnis.

Ağız, boyun ve kulp kırık ve eksiktir ve yüzeyde aşınma görülür. Uzun silindirik boyunlu $^{6}$, kaideye doğru daralan silindirik gövdeli, yüksek disk kaideli, boyundan omuza bağlanan ince, dikey şerit kulpludur. Boyun kavisli, omuzlar içe doğru keskin profillidir. Gövde kaideye doğru hafif daralarak inerken, kaideye yaklaştığı noktalarda daralma artar ve kısa bir kaide boynu oluşturur.

Boyun bitimi ve omuzda, iki sıra 1şın demeti yer alır. Boyun bitiminde yer alan ışın demeti daha kısa iken, omuz üzerinde yer alan ışın demeti daha uzun verilmiştir. Gövdenin yarısı, yukardan itibaren aşağıya doğru iki sıra yatay bant, meander motifi, tek sıra yatay bant, üç sıra halinde kafes motifi ve tek sıra yatay bant bezemelidir. Bu sıralama (meander hariç) gövdenin ortasında ana motif olarak yer alan, ters - düz - ters biçimde verilen üç adet açı ve büyük palmet bezemesinden sonra da devam eder. Ortada yer alan palmet bezemenin her iki yanında spiral motifi işlenmiştir. Gövdenin alt bölümü inceli-kalınlı yatay bantlıdır ve kaide üstü dahil, kabı çepeçevre saracak şekilde siyah firnislidir. Kaide yanları ve alt bölümünde kırmızı kahve astar kullanılmıştır. Kaidenin yan çeperleri arasındaki bölüm ince siyah firnis bantlıdır. Bezeme dış konturları, yüzeysel biçimde kazıma olarak verilmiştir.

\section{No. 4 (Res. 5, Fig. 4)}

Müze Envanter No: 2371, Kazı Envanter No: 06BM16 - PT05

Yükseklik: $13.9 \mathrm{~cm}$, gövde çapı: $4.5 \mathrm{~cm}$, kaide çapı: $3.3 \mathrm{~cm}$, cidar: $0.4 \mathrm{~cm}$

Hamur: Munsell 5YR 8/2 (pinkish white)

Astar/Firnis: astar Munsell 5YR 6/6 (reddish yellow), parlak ince siyah firnis.

Kulp, omuz ve gövde de yapıştırmalar mevcuttur; yüzeyde aşınma görülür. Dışa doğru hafif yuvarlatılmış huni (trompet) ağızlı, uzun silindirik boyunlu, kaideye doğru daralan silindirik gövdeli, alçak disk kaideli, boyundan omuza bağlanan ince, dikey şerit kulpludur. Boyun kavisli, omuzlar içe doğru keskin profillidir. Gövde kaideye doğru hafif daralarak inerken, kaideye yaklaştı̆̆ 1 noktalarda daralma artar ve kısa bir kaide boynu oluşur. Gövdenin kaideye doğru gösterdiği daralma no.3.'e göre daha keskince olup, kaide boynu daha uzundur.

${ }^{6}$ No.3 ağız kırık ve eksik olmasına karşın, benzer örneklerden dışa doğru çekiklik gösteren yuvarlatılmış huni (trompet ağızlı), uzun silindirik boyunlu olduğu anlaşılmaktadır. 
Ağız içi ve dışı, huni formun bitimine kadar siyah firnislidir. Boyun bitimi ve omuzda ışın demeti görülür. Gövde üzerinde yatay bantlar arasında, gövdenin yarısını kaplayacak biçimde üç adet kalın yapraklı açık palmet bezeme yer alır. Palmet bezemeleri birbirine sarmal dallarla bağlıdır ve her palmetin alt kısmına iki adet spiral işlenmiştir. Gövdenin alt bölümü, kaide üstü dâhil siyah firnislidir. Kaide yanları ve alt bölümü astar zeminli bırakılmıştır. Kulp dikey siyah firnis bantlıdır. Bezeme dış konturları, yüzeysel biçimde kazıma olarak verilmiştir.

Palmet bezemeli örneklerden no.3'ün "Beldam Ressamı ve Atölye Grubu" ile bağlantıll, gövde üzerinde ters-düz-ters biçimde palmet bezeme işlenen örnekler arasında yer aldığ ve MÖ 5. yüzyılda sıklıkla karşılaşılan örneklerden olduğu anlaşılmaktadır7. MÖ 440-400 yıllarına tarihli Karaçallı Nekropol örneği (Çokay-Kepçe 2006: 24, 92, Kat. No. SF49), Karaman (Doksanaltı 2011: 96-97, Fig.13-14), Silifke (Zoroğlu 2009: 1-2, Lev. II, Fig. 3, 5-6) ve Anamur (Yıldız 2013, Res.45-50, Çiz.10-11) müzelerinde korunan MÖ 5. yüzyıla tarihli lekythoslardan anlaşıldığı kadarı ile Batı Anadolu ve Akdeniz Batı -Kilikya kıyılarında sıklıkla rastlanan bir lekythos formudur. Palmet bezemeli diğer örnek olan no.4'ün ise kabul gören benzer örneklere göre, "Beldam - Haimon atölyeleri" ile ilişkili lekythoslar arasında yer aldığı ve MÖ 5. yüzyılın ikinci çeyreğinde ve ortalarında sıklıkla rastlanan bir biçim olduğu görülmektedir8. Benzer lekythos örnekleri içinde, Börükçü lekythoslardan no.3 özellikle Silifke Müzesi'nden lekythos (Zoroğlu 2009: 2, Lev. II, Fig. 6 (504)) ile gövde formu ve palmet yapraklarının uzanma biçimi ile çok yakındır. no.4 ise Hamburg Müzesi'nden (Brümmer 1976: 47, Lev.32, no 6- 7) bir örnek ile bezeme işlenişi olarak büyük benzerlik içindedir. Bu benzerlikler no.3 ile Silifke Müzesi; no.4 ile Hamburg Müzesi örneklerinin aynı atölye grubundan olmaları dışında, aynı bölgelerde veya aynı atölyelerde üretilmiş olabileceklerine de işaret etmektedir. Ayrıca no.3 örneğinin Batı Anadolu veya Akdeniz Kilikya atölyelerinde üretilen Attik etkili yerel bir eser olduğu da düşünülmektedir.

\section{Siyah Gövdeli Lekythos}

\section{No. 5 (Res. 6, Fig. 5)}

Müze Envanter No: 2832, Kazı Envanter No: 07BM17-PT02

Yükseklik: $12.6 \mathrm{~cm}$, gövde çapı: $4.6 \mathrm{~cm}$, kaide çapı: $3.3 \mathrm{~cm}$, cidar: $0.4 \mathrm{~cm}$

Hamur: Munsell 5YR 7/4 (pink)

Astar/Firnis: astar Munsell 5YR 4/3 (reddish brown), parlak ince siyah firnis.

Ağız tamamen, boyun büyük oranda kırık ve eksiktir. Boyun kavisli, omuzlar belirgin biçimde içe doğru keskin profillidir. Kaideye doğru daralan silindirik gövdeli, aşağı doğru hafifçe daralan yüksekçe disk kaideli, boyundan omuza bağlanan ince, dikey şerit kulpludur. Silindir gövde kaideye doğru hafif daralarak iner, kaideye yaklaştı̆̆ı noktalarda daralma artar ve kısa bir kaide boynu oluşturur. Ağız, boyun ve gövde formu no.1- 3 ile daha yakınken, disk kaideli olması ile no.4'e benzerdir.

Boyun bitimi ve omuz üstünde ışın demeti yer alır. Gövdenin tamamı ve kaide üstü, arada kahveye çalan siyah firnislidir. Kaide yan çeperi ve kaide altı kırmızımsı-kahve, astar zeminli bırakılmıştır. Bu formda ve bezemede olan örneklerden anlaşıldığı kadarı ile bu

\footnotetext{
7 Beldam Atölyesi ile ilişkilendirilen bu tip örnekler için bk. Kurtz 1975: 152-153; Boulter 1963: 118, Lev.37, Fig.B4; Sidorova 1996: 43, Fig.2-8; Alkaç 2006, 59-60, fig. 6; Çokay 2010, 213 vd.

8 Benzer gruplar için bk. Moignard1989: 19, Lev.16, no 8-10; Ederhard1973: 40, Lev.38, no 2; İşler 1973: 28, Lev. 20, no 13-14; Büsing - Kolbe 1977: 77-78, Lev.37, no 3-4; Giudice 1979: 27-28, Lev.44, no 1-12; Frere 1997: 39, Lev.22, no 1-3, no 5; Chease 1942: 31, lev. XX, no 7-8; Brümmer 1976: 47, lev.32, no 4-7;
}

SEFAD, 2017 (38): 481-492 
grup lekythos MÖ 5. yüzyılda yaygındır ve serinin erken örnekleri MÖ 6. yüzyıla kadar gitmektedir9. Yaptığımız taramalardan no.5'in benzer örnekler içinden özellikle Atina Agora'dan (Sparkes -Talcott 1970: Lev.38, no 1119) ve Karaçallı Nekropolü'nden (Çokay Kepçe 2006: 91, SF 2) MÖ 450 yıllarına tarihli siyah zeminli lekythoslara, hem form hem de fırça darbelerinin gövdeye uygulanışı ile çok yakın olduğu görülmektedir.

\section{SONUÇ}

Yaptığımız çalışmalarda Börükçü siyah figürlü lekythosların "Shoulder lekythos standart tip" grubu örneklerinden olduğu anlaşılmış ve no.1, no. 2 ve no. 3'ün gövde üzerinde yer alan bezeme ve forma göre "Beldam Ressamı ve Atölyesi Grubu", no.4'ün "Beldam Haimon atölyeleri" ile ilişkili örneklerden oldukları tespit edilmiştir. Benzer ve yakın örneklere ve çağdaş kap formlarına göre, ele aldığımız Börükçü siyah figürlü lekythosları MÖ 5. yüzyılın ilk yarısına tarihlendirilmiştir.

Börükçü siyah figürlü lekythosları çok kaliteli olmayan işçilikleri ile ikinci derece işçiliğe sahiptirler. Batı Anadolu ve Akdeniz kıyı bölgelerinden, özellikle de Batı Kilikya'da üretildiği belirlenen Karaman, Silifke, Anamur, Alanya Müzelerinde korunan örnekler ile bezeme işlenişi ve ikinci derece işçilikleri bakımından çok yakın durdukları tespit edilmiştir. Akdeniz-Batı Kilikya yerel atölyelerinde üretildiği kabul edilmiş olan bu imitasyon örneklerle özenli olmayan ikinci derece işçilikleri yanında, bezeme işlenişi olarak da çok yakın olmaları, Börükçü lekythosların ithal örnekler olmaktan çok, Yunanistan etkili, Akdeniz - Batı Kilikya bölgesi yerel atölyelerinde üretilmiş imitasyon eserler olduklarını düşündürtmektedir.

\footnotetext{
9 Benzer örnekler için bk. Sparkes - Talcott 1970: 153, Lev.38, no 1114-1119; Çokay - Kepçe 2006: 41, 91, SF 1-2; Haspels 1936: Lev.50-54; Chease 1942: Lev.XII, no 10-12; Büsing -Kolbe 1977: 77, Lev.36, no 5-7; Cesare 1991: Lev.23, no 5; Coşkun 2004: 102-103, Lev.20, Fig.91-92: Ederhard 1973: 41, Lev.38, no 7; Frere 1997: 52-53, Lev.34, no 3-9; Robinson 1933: 76, Lev.50, no 33-34.
} 


\section{SUMMARY}

In this study, five black- figured lekythoi have been examined from Börükçü rural area which is located in the west of Aladağ, within the boundaries of the ancient Caria region ( in modern Muğla-Yatağan). Four of the Börükcü lekythoi (no1-2, 4-5), were found in a grave, the other in a sondage (no.3). All of the Börükcü black-figure lekythoi are considered in the form of 'Shoulder Lekythos - standart type' and they belong to the Richter - Milne "Type II - Shoulder set off from body" lekythoi group. It is ascertained that among the lekythoi, number 1, 2, 3 are related to "the group of Beldam Painter and its workshop group" and number 4 is related to "the group of Beldam - Haimon Workshop" according to their forms and palmettes and ivy decorations on their bodies. These types of lekythoi are mostly regarded as goods imported from Greece. However, as we can see in the preserved samples in the museums of Karaman, Silifke, Anamur and Alanya, second quality lekythoi, which could not have been imported, commonly exist. These samples, most of which were determined to have come from Western Mediterranean-Cilicia, are approved as the imitation goods produced in Western Mediterranean-Cilicia workshops. Dated to the first half of the fifth century B.C., Börükçü black figured lekythoi have some close resemblance to those imitation samples with their second quality craftmanships and ornaments. Börükçü lekythoi, with their resemblances and second degree inelaborate craftmanships, are considered to be the samples of those imitation products coming from the local workshops of Western Mediterranean-Cilicia. It is highly important that these forms were found in inner regions such as Börükçü, as it illustrates the existence of coastal trade relations between inner parts of Western Anatolia and Western Mediterranean-Cilicia in the 5th century BC. 


\section{KAYNAKÇA}

ALKAÇ, Erkan (2006). “Tarsus Müzesinde Bulunan Bir Grup Lekythos”. Olba (XIV). Mersin: Kaam Yayınları. 53-70.

BOARDMAN, John (1974). Athenian Black Figure Vases. A Handbook. London: Thamesand Hudson.

BOARDMAN, John (1996). Rotfigurige Vasen aus Athen die Klassische Zeit. Mainz: von Zabern.

BOARDMAN, John (2003). Siyah Figürlü Atina Vazoları. çev. Gürkan Ergin. İstanbul: Homer Kitabevi.

BOULTER, Catherine (1963). Graves in Lenormant Street, Athens, Hesperia 32. 113-137.

BOUZEK, John (1990). Greek Pottery in the Black Sea Area. Prague: Charles University.

BRÜMMER, Elfriede (1976). Corpvs Vasorvm Antıqvorm, Hamburg, Museum Für Kunst und Gewerbe, Hamburg Band I, Deuschland, Band 41. München: I. C.H. Beck'sche Verlagsbuchhandlung.

BÜSING-KOLBE, Andrea (1977). Corpvs Vasorvm Antıqvorm, Mainz, Römisch-Germanisces Zentralmuseum. Mainz Zentral Museum Band I, Deutschland Band 42. München: C.H. Beck'sche Verlagsbuchhandlung.

BÜYÜKÖZER, Aytekin (2012). "Börükçü'deki Atölyeler Mahallesi ve Zeytinyağı Üretimi" Stratonikeia'dan Lagina'ya: Ahmet Adil Tırpan Armağanı /From Stratonikeia to Lagina: Honour of Ahmet Adil Tırpan. ed. B. Söğüt. İstanbul: Ege Yayınları. 127-146.

BÜYÜKÖZER, Aytekin (2013). "A Tomb from Börükçü Necropolis". Anados (11). 38-48.

CESARE, Monika De (1991). Corpvs Vasorvm Antıqvorm, Vibo Valentia Museo Statele "Vito Capialbi'. İtaly LXVII. Roma : 'L' Erma Bretschneider. Verlagsbuchhandlung.

CHEASE, George H - PEASE, Mary Zelia (1942). Corpvs Vasorvm Antıqvorm, United States of America Fogg Museum and Galatian Collectıons, Fasikül 8 : Harvard University Press Cambridge, Massachusetts.

COŞKUN, Güner (2004). “Daskleion'da Bulunan MÖ 5. Yüzyıl Siyah Firnisli Attika Seramikleri". Olba (X): Mersin: Kaam Yayınları. 98-134.

COŞKUN, Güner (2006). “Daskleion'da MÖ 4.Yüzyıl Siyah Firnisli Attika Seramikleri”. Olba (XIII): Mersin: Kaam Yayınları. 81-114.

ÇOKAY-KEPÇE, Sedef (2006). Antalya Karaçallı Nekropolü / The Karaçallı Necropolis near Antalya. İstanbul: Suna ve İnan Kıraç Akdeniz Medeniyetleri Araştırma Enstitüsü.

ÇOKAY-KEPÇE, Sedef (2010).“Pamphylia'da Klasik Dönem'de Saptanan Yerel ve Yunan Unsurlar Üzerine Bir Değerlendirme”.Colloquium Anatolicum IX. 213-227. İstanbul: Türk Eski Çağ Bilimleri Enstitüsü.

DOKSANALTI, Ertekin (2011). “Karaman Müzesi'nden Bir Grup Siyah Figürlü Lekythos". Olba (XIX): Mersin: Kaam Yayınları. 81-105.

EDERHARD, Paul (1973). Corpvs Vasorvm Antıqvorm, Leipzig Antikenmuseum Der Karl Marx Universitat, Leipzig Band 2. Berlin: Akademie - Verlag.

FRERE, Dominiqu (1997). Corpros Vasorvm Antıqvorm, Mantes Musee Dobree. Fransa Fasikul 36. Paris: Diffusion de Boccard.

GENIERE, Juliette De La (1971). Corpvs Vasorvm Antıqvorm, İtalia, Palermo - Collezione Mormino Bando Di Sicilia. I. Roma: "L' Erma di Bretschneider.

GIUDICE, Filippo (1979). Corpus Vasorvm Antıqvorm, Museo Archeologico Nazionale Di Gela Collezıone IV. İtalıa LVI. Roma: Multıgrafiga Editrice. 
GIDER BÜYÜKÖZER, Zeliha (2014). "Börükçü Nekropol Alanından Bir Arkaik Mezar". Tüba-Ar (17) : Türkiye Bilimler Akademisi Enstitüsü. 111-128.

HASPELS, Caroline Henriette Emilie (1936). Athenian Black Figured Lekythoi. Paris: De Boccard.

İ̧LER, Hans Peter (1973). Corpus Vasorum Antıqvorm, Öffentliche Sammlungen, Zurich I, Schweiz 2. Bern: Verlag Herbert Lang

KANOWSKI, Maxwell George (1984). Containers of Classical Greece: A Handbook of Shapes. New York: University of Queensland Press.

KNIGGE, Ursulla (1976). Kerameikos: Ergebnisse Der Ausgrabungen, Der Südhügel, Band IX. Berlin: De Gruyter.

KURTZ, Donna Carol (1975). Athenaian White Lekythoi. Oxford: Pattern and Painters.

MOIGNARD, Elizabeth (1989). Corpvs Vasorvm Antıqvorm, Great Britain, Fasikül 16, The National Museums of Scotland Edinburg, Oxford: Oxford University Press.

RICTER, Gisela Marie Augusta - MILNE, Marjorie Josephine (1935). Shapesand Names of Athenian Vases. New York: Metropolitan Museum of Art.

RISSER, K Martha (2003). "Corinthian Archaic and Classical Pottery: The Lokal Style". Corinth: The Centenary 1896-1996 (Ed. C.K. Williams - N. Bookids). Corinth XX. Athens: The American School of Classical Studies at Athens. 157-166.

ROBINSON, David Moore (1933). Excavations at Olynthus V: Mosaics, Vases and Lamps of Olynthus Found in 1928 and 1931. Baltimore: John Hopkins University.

SIDOROVA, Natalya (1996), Corpvs Vasorvm Antıqvorm, Pushkin Museum of Fine Arts Moskow. Roma: "L' Erma di Bretschneider.

SÖĞÜT, Bilal (2012). "Börükçü 2003-2006 Yılları Kazıları". Stratonikeia'dan Lagina'ya: Ahmet Adil Tırpan Armağanı /From Stratonikeia to Lagina: Honour of Ahmet Adil Trrpan. ed. B. Söğüt. İstanbul: Ege Yayınları. 553-586.

SPARKES, Brian - Lucy TALCOT (1970). The Athenian Agora XII, Part 1-2. Black and Plain Pottery of the 6th, 5th, and 4th Centuries B.C. Princeton. New Jersey: The American School of Classical Studies At Athens.

TIRPAN, Ahmet Adil - BÜYÜKÖZER, Aytekin vd. (2016). "Arkaik Dönemde Börükçü (Koliorga?)"Antahsum. Prof. Dr. Ahmet Ünal'a Armağan, Studies in Honour of Ahmet Ünal. ed. S. Erkut-Ö. Sir Gavazi). İstanbul: 553-586.

TIRPAN, Ahmet Adil - BÜYÜKÖZER, Aytekin. (2010). “Börükçü 2 Numaralı Zeytinyağ1 Atölyesi" Olive Oil and Wine Production in Anatolia During Antiquity International Symposium Proceedings/ Antik Çă̆da Anadolu'da Zeytinyağı ve Şarap Üretimi Uluslararası Sempozyum Bildirileri. ed. Ü. Aydınoğlu, A. K. Şenol. İstanbul. Ege Yayınları. 227-240.

TUNA-NÖRLING, Yasemin. (1999). Daskyleion I: DieAttische Keramik. İzmir: Ege Üniversitesi.

ZOROĞLU, Kamil Levent (2009). Corpvs Vasorvm Antıqvorm, Silifke Museum, Türkish Republic I. Istanbul: İstanbul Arkeoloji Müzesi. 


\section{EKLER 10}

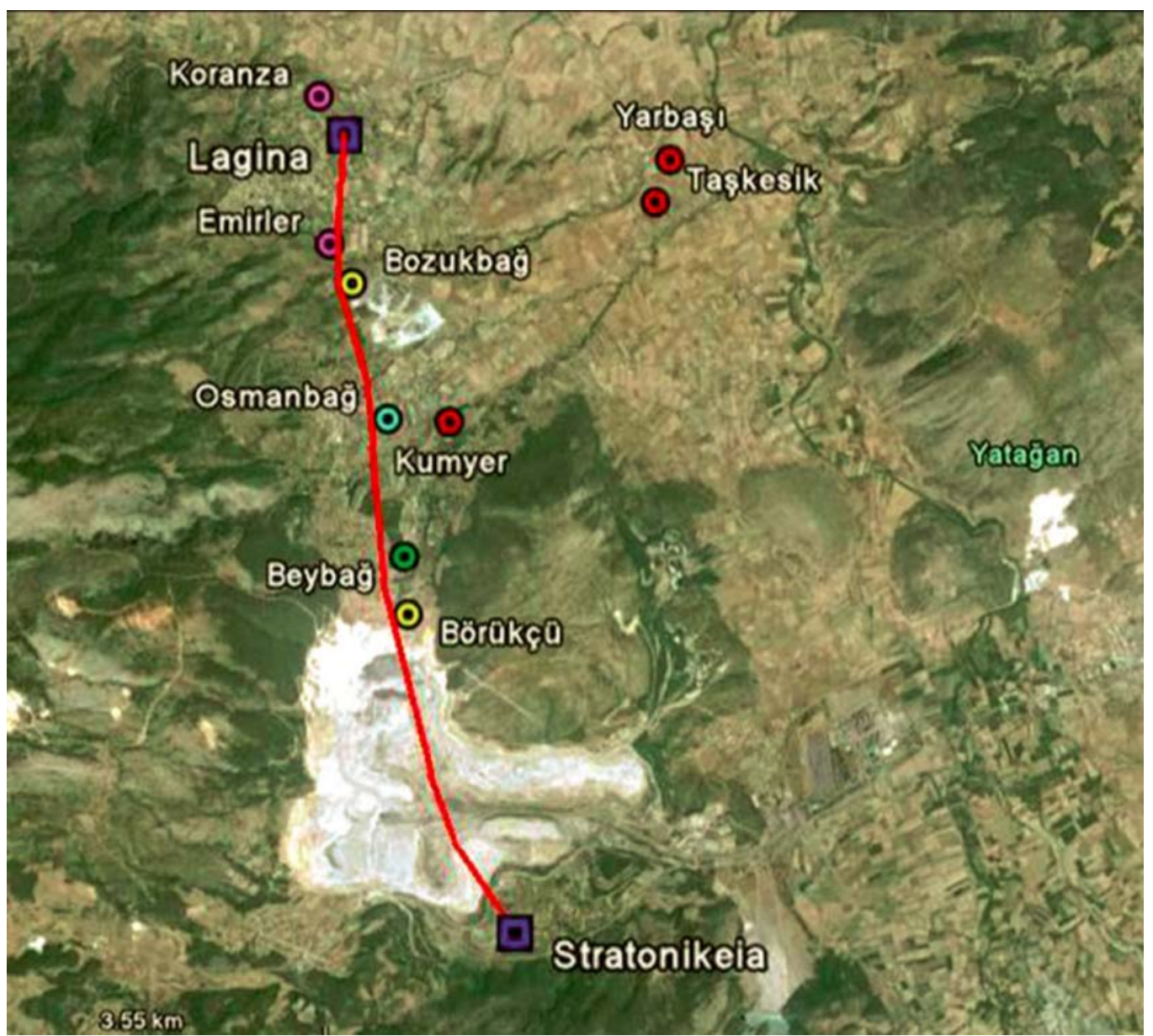

Res. 1 Stratonikeia ile Lagina Arasında Bulunan Kutsal Yol ve Börükçü Yerleşimi (Türkiye Kömür İşletmeleri Yatağan Geli Müessesi arşivinden alınmıştır).

${ }^{10}$ Figür bölümünde yer alan bazı çizimlerin el örnekleri yazarında çalışma içinde yer aldığı Lagina Kazı arşivinde alınmıştır. Çizimlerin bilgisayar ortamına geçirilmesi ise Songül Karabıçak, Serap Karaoğlan ve yazara aitti. Kaynakçası belirtilmeyen resimler yazara aittir. 


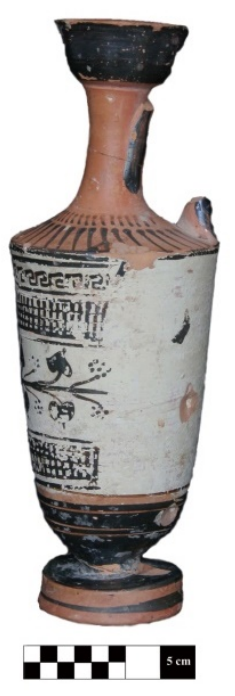

Res. 2 (No.1)

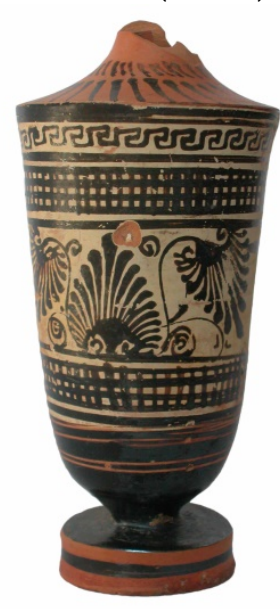

Res. 4 (No.3)

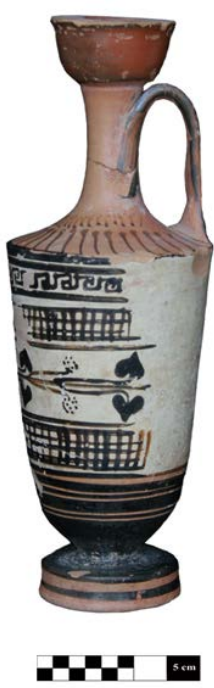

Res. 3 (No.2)

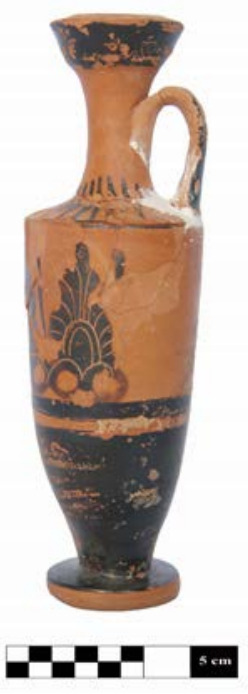

Res. 5 (No.4)

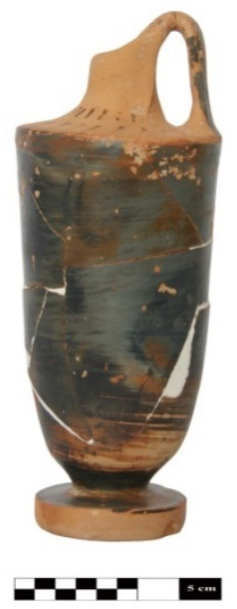

Res.6 (No.5) 

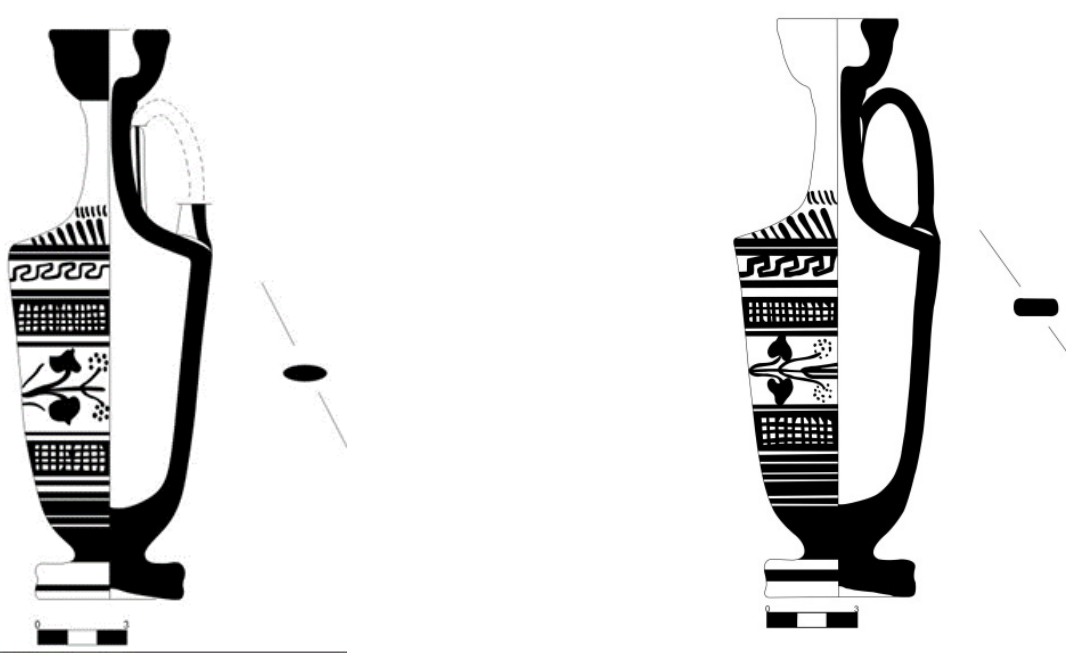

Fig. 1 (No.1)

Fig. 2 (No.2)

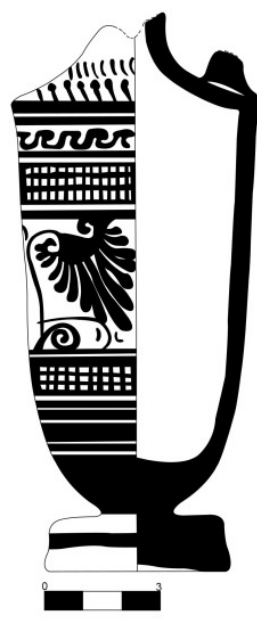

Fig. 2 (No.3)

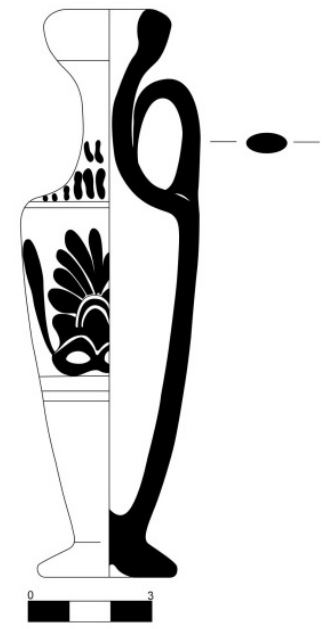

Fig. 2 (No.4)

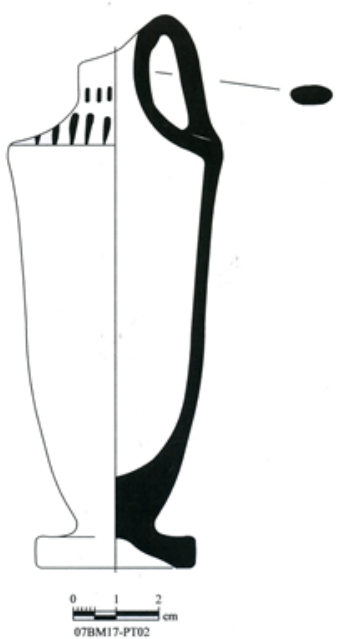

Fig.5 (No.5) 